\title{
Religiosidad y prensa escrita en Oaxaca: Apuntes para iniciar un estudio detallado
}

\section{Eduardo García V.}

\section{Introducción}

Recurrentemente se ponen en la mesa del debate nacional temas que el tiempo ha convertido en clásicos. Asuntos como: "Las relaciones Iglesia-Estado" o "El papel de la Iglesia en la política" constantemente se someten a discusión, no sin caer en prejuicios y lugares comunes.

Esta discusión nos parece que ha dejado a un lado un asunto mucho más amplio, y que está en el fondo de la disputa: la relación entre religión y vida social. Tal omisión, como señala el sociólogo Manuel Canto:

...ha evitado la discusión y el saldo de cuentas sobre un asunto fundamental para toda cultura, para todo proceso de reconstrucción de identidades: los contenidos religiosos que al construir significados confieren sentido a la existencia y se constituyen en elementos fundantes de las formas de agregación e identidad social y por tanto, de la cultura nacional. ${ }^{1}$

Esos contenidos religiosos, capaces de construir significados tan importantes, sistematizados se convierten en formas simbólicas, mismas que no son otra cosa que organización significante que puede transmitirse de diversas maneras y aplicarse a diversos ámbitos.

En la era mediática, cuando esa transmisión se realiza a través de un canal de comunicación — que puede ser la televisión, el cine, la radio, el video o la

1. Véase el prólogo de El botín sagrado: La dinámica religiosa en Oaxaca, obra de Enrique Marroquín y elaborado por Manuel Canto Chac. En la Colección "Del Barro Nuestro", IISUABJO-Comunicación Social, Oaxaca, México, 1992, página 6. 
prensa escrita-, es evidente que se afecta a la forma simbólica. Al respecto, Antonio Paoli afirma:

...los medios de comunicación son modos mediante los cuales se organiza físicamente la emisión, transmisión y recepción de los mensajes. Es claro que los procesos técnicos ofrecen marcos a nuestro pensamiento y que al operar tienden a ofrecer modos de asociación a nuestros patrones de interpretación. ${ }^{2}$

La afectación sobre la forma simbólica ejercida por los medios de comunicación es importante, porque está en juego —como explica Paoli- la dinámica intencional del conocimiento que lleva a las audiencias, tanto a entender ciertos aspectos de las cosas, como a bloquear el entendimiento de otras. $\mathrm{Y}$ es aquí donde comienza el problema: en el momento en que los medios, que son escenarios en donde un relato social se pone en escena, ${ }^{3}$ regidos por las leyes del mercado y por sus propios intereses políticos, bloquean la transparencia y requieren ámbitos de sentido donde otros no pueden mirar. Cuando se da ese bloqueo en torno a lo religioso, como nos afirma Garma Navarro: “...los prejuicios y estereotipos se acentúan más hacia aquellos sectores que son percibidos como los más lejanos y extraños con respecto a la colectividad propia". ${ }^{4}$

Entonces se origina un sentimiento de rechazo que muchas veces provoca reacciones que pueden derivar en formas de represión o en la exclusión de las minorías.

Este trabajo plantea realizar una aproximación a cómo se reconstruyen los significados de lo religioso en un medio de comunicación y en una sociedad como la oaxaqueña, hasta hace poco tiempo totalmente católica, y en tiempos de un profundo reacomodo caracterizado por la decadencia y aparición de nuevas y viejas creencias e instituciones que giran en torno a lo divino. El periódico aquí es analizado como escenario en donde se representa el fenómeno religioso convertido en noticia.

El presente documento se basa en un análisis de contenido hemerográfico, y se limita a ofrecer un balance cuantitativo de los asuntos, personajes e instituciones religiosas que fueron mencionados por la prensa de Oaxaca, en términos informativos, durante los meses de abril, mayo y junio de 1998.

Trataremos de desentrañar las causas que incidieron en el hecho de que personajes y temas relacionados con lo religioso aparecieran en los diarios, así

2. Véase Antonio Paoli: Juego simbólico y utopia.

3. Néstor García Canclini: Culturas híbridas: estrategias para entrar y salir de la modernidad, Grijalbo, México, 1989, página 339.

4. Véase Carlos Garma Navarro: "Percepciones de católicos y evangélicos", en Sectas o Iglesias: Viejos o Nuevos Movimientos Religiosos, Elio Mansferer (comp.), ALER-Plaza y Valdés, México, 1998, página 221. 
como el contexto en el que se ubicaron dichas menciones. Además, como un elemento de apoyo que nos permitirá formular algunas conclusiones, se dan a conocer los resultados de una encuesta sobre creencias, valores y prácticas religiosas de los periodistas que laboran en los matutinos analizados.

En esta investigación se partió de la hipótesis de que la prensa oaxaqueña, marcada por una fuerte tendencia pro-católica conservadora, está excluyendo de sus páginas a las minorías religiosas en emergencia y a los propios grupos católicos disidentes, contribuyendo con ello a propagar la idea de que la pluralidad religiosa es disgregación y ruptura del orden, y que tal heterogeneidad es fuente de contaminación y deformación de las purezas culturales.

\section{Oaxaca en cifras}

En sus $95,000 \mathrm{~km}^{2}$, Oaxaca cuenta con una población superior a los tres millones seiscientos mil habitantes, de los cuales, 70 por ciento pertenece a alguno de los 16 grupos étnicos que viven en el estado.

Esta entidad del sureste mexicano está dividida políticamente en 570 municipios, y cuenta con 5 mil localidades, de las cuales, sólo cinco agrupan a más de 100 mil habitantes.

Según un estudio realizado por investigadores del Instituto Tecnológico y de Estudios Superiores de Monterrey (ITESM),${ }^{5} 25$ por ciento de los oaxaqueños no percibe ninguna remuneración y los campesinos obtienen, en promedio, un ingreso per capita mensual de 157 pesos.

La media de edad es de 20 años; el promedio de escolaridad es de seis años de educación primaria, y en relación con el resto de los estados del país Oaxaca observa el segundo lugar en materia de analfabetismo. Además, menos del 0.55 por ciento de los profesionistas cuentan con estudios de Posgrado y, de acuerdo con el estudio que realizó el Tecnológico de Monterrey, campus ciudad de México, entre los estados de la República Oaxaca ocupa el lugar 31 en materia de competitividad.

Sus pobladores - sumamente pobres-son profundamente religiosos, pero en los últimos años han experimentado cambios sustanciales en la forma de relacionarse con lo divino, resintiendo los efectos de un fenómeno que rebasa su territorialidad, y que se inscribe en una lógica no sólo nacional sino continental: la expansión del protestantismo.

5. El estudio fue realizado por investigadores del Instituto Tecnológico y de Estudios Superiores de Monterrey, campus ciudad de México. Véase Estudio de Competitividad, ITESM, México, 1998. 
Profundo conocedor de ese tema, David Stull ${ }^{6}$ asegura que en el próximo siglo un tercio de América Latina se habrá convertido al protestantismo.?

Para el caso específico de México, varios especialistas piensan que uno de los fenómenos más significativos de las postrimerías de este siglo será la recomposición del campo religioso, resultante de la proliferación de nuevas minorías religiosas de cuño protestante. ${ }^{8}$

De acuerdo con los estudios realizados por el Instituto Nacional de Estadística, Geografía e Informática (INEGI), en tan sólo veinte años la población protestante del país creció 144 por ciento más que la católica. Esto significa que, en apenas dos décadas, en México la población creció 40 por ciento y los católicos sólo lo hicieron en 30 por ciento, a diferencia de los protestantes, quienes se expandieron en 174 por ciento.

En lo que concierne al estado de Oaxaca, el crecimiento en el número de conversos y practicantes de otras religiones resultó muy significativo en ese mismo periodo, al haberse quintuplicado la cantidad de personas que practican religiones diferentes a la católica, ${ }^{9}$ situación que ubicó a esa entidad en el sexto lugar dentro de los estados de la República en el que existen más conversos. El crecimiento del protestantismo en Oaxaca principalmente se presenta en comunidades rurales; es decir, en poblaciones menores a 2,500 habitantes. ${ }^{10}$

No obstante, si se toma en cuenta que ante el empobrecimiento cada vez más acentuado del campo mexicano, provocado, por la destrucción de las viejas formas productivas y la falta de oportunidades de empleo, el número de inmigrantes en las ciudades locales se está elevando notoriamente. Por tanto, pronto

6. Véase David Stull: Se vuelve protestante América Latina, citado por Gregorio Selser. En el capítulo "Viajes a América Latina", de Iglesia - Estado en México, CAM, CEE, CENCOS, CRT. México, 1991, página 115.

7. Sobre la expansión de los protestantismos en México, Jean Pierre Bastian posee varios títulos muy útiles para la comprensión de ese fenómeno religioso. A continuación menciono dos: "Protestantismo y política en México", en Revista Mexicana de Sociología, 1981 y "Protestantismo y revolución constitucionalista en México, 1910-1920", Taller de Teología, 1982.

8. INEGI: "XI Censo General de Población y Vivienda". México, 1990.

9. Una de las características de este proceso es el desplazamiento del crecimiento protestante de las zonas urbanas y del norte del país, hacia las zonas fronterizas, especialmente las rurales del sureste; es decir, en estados que concentran al $22.5 \%$ del total de feligreses de dichas confesiones, a los que Oaxaca colabora con otros con otro $5.5 . \%$ más, ocupando el sexto lugar en el protestantismo nacional -un lugar más arriba que en la década anterior. De ese modo, mientras que en los últimos 20 años la feligresía protestante de todo México pasó del $1.8 \%$ al 4\% de la población total, en Oaxaca, el crecimiento protestante se disparó del $1.5 \%$ al $7.3 \%$. Este crecimiento en el estado ha hecho perder su monopolio religioso a la Iglesia católica, pues ésta sólo creció el $15.4 \%$ mientras que la población lo hizo el $50 \%$ y todas las demás opciones contempladas lo hicieron por encima de ella". En Gilberto Giménez: Sectas religio-" sas en el sureste. Aspectos sociográficos y estadísticos, CIESAS del Sureste SEP.CONAFE, Cuadernos de la Casa Chata, número 161, 1988, página 13.

10. Enrique Marroquín Zaleta (coord.), iPersecución religiosa en Oaxaca? Introducción. Serie Disha, Instituto Oaxaqueño de las Culturas, México, 1995, página 11. 
podríamos estar presenciando una acelerada diversificación de lo religioso en las estructuras sociales urbanas oaxaqueñas.

En Oaxaca las minorías religiosas están pasando a ocupar espacios cada más amplios en el ámbito estatal, lo cual supone la creación de nuevas formas de relación y convivencia social que van más allá de los altares y se instalan en la cotidianidad.

Lo anterior pone de manifiesto la imperiosa necesidad de conocer los procesos de reconfiguración del campo religioso, pero también la forma en la cual la ciudadanía se está poniendo en contacto con esa nueva realidad, profunda y delicada a la vez, de la cual los fantasmas del fundamentalismo no están lejos, razón que vuelve indispensable analizar cómo se está percibiendo y difundiendo este proceso de transformación religiosa, considerando en el análisis a los medios de comunicación locales, los cuales son la forma más directa para obtener la información que, en mayor o menor grado, habrá de influir en buena parte de las conductas del público oaxaqueño.

En Oaxaca, desafortunadamente la investigación sobre los asuntos directamente relacionados con la comunicación y los medios es muy escasa, situación por la cual hacer una aproximación al campo mediático estatal resulta complicado y tiene que realizarse a partir de la información que concentran algunos órganos de gobierno como algunas empresas periodísticas.

Según un estudio realizado por la Secretaría Técnica del Poder Ejecutivo, elaborado en 1996, la radio local es el medio de comunicación más socorrido en Oaxaca para obtener información noticiosa (45 por ciento). A la radio le siguen la televisión (33.3 por ciento) y la prensa (5.1 por ciento).

El mismo estudio revela que de ese 5.1 por ciento que se informa a través de la prensa, sólo el 34.6 por ciento - aproximadamente 65,000 personas-, quienes constituyen 1.7 por ciento de la población total, leen al menos un periódico diariamente. ${ }^{11} \mathrm{El}$ porcentaje de lectores de la prensa de Oaxaca se distribuye de la siguiente manera: Noticias (51 por ciento); El Imparcial (15 por ciento); Excélsior (5 por ciento); El Sol del Istmo (12 por ciento); La Jornada (3 por ciento); otros (14 por ciento).

Con las reservas del caso, las cifras anteriores nos permiten apreciar que la radio local es el principal medio informativo de los oaxaqueños; sin embargo, hay que tomar en cuenta que los contenidos de los noticiarios radiofónicos estatales en buena medida están conformados por las noticias y comentarios que los conductores extraen de los periódicos locales.

11. Existen, sin embargo, fuentes que señalan que el porcentaje de personas que leen diarios en esa entidad es todavía menor. Un estudio realizado por el director-fundador del diario local Cantera, Razhy González, en 1997, establece que sólo el 0.7 por ciento de los habitantes de Oaxaca leen diariamente la prensa, porcentaje que equivaldría a unas 25,200 personas. 
En realidad son muy pocas las empresas radiales de Oaxaca que cuentan con equipos propios de producción de noticias, y a menudo sus noticiarios se conforman de andanadas de opiniones del público, el cual expresa sus puntos de vista respecto a los comentarios hechos por el locutor-periodista en turno.

No es aventurado afirmar que la mayoría de los reporteros que trabajan en los noticiarios radiofónicos locales también laboran en la prensa escrita local o se desempeñan como corresponsales de algunos medios informativos nacionales, y que laboran en la radio para incrementar sus ingresos.

Después de la radio, la televisión es el segundo medio de información para los oaxaqueños (33 por ciento). Pero es a la televisión comercial abierta, con cobertura nacional, a la que corresponde ese porcentaje, no a la que se produce y se transmite en y desde la ciudad de Oaxaca - la cual también tiene espacios informativos. El estudio del Gobierno de Oaxaca que he citado, establece que sólo 0.9 por ciento de la población estatal ve los informativos de la Corporación Oaxaqueña de Radio y Televisión —de carácter gubernamental.

Como es evidente, la prensa es el medio que va a la zaga de las preferencias mediáticas de los oaxaqueños, con 5.1 por ciento. Las causas pueden ser muchas, pero seguramente las más importantes son el analfabetismo real y funcional, la dispersión poblacional que dificulta la rentabilidad de la distribución y, por supuesto, el muy bajo poder adquisitivo de los oaxaqueños.

\section{Consideraciones metodológicas}

Aún cuando se ha visto que la prensa escrita es el medio menos utilizado por la ciudadanía de Oaxaca para informarse, el hecho de que ésta brinde soporte a los noticiarios radiofónicos locales, y la posibilidad de tener acceso a los archivos hemerográficos en los que se pueden cotejar los contenidos de dichas publicaciones, fueron los motivos que sirvieron para fundamentar la decisión de que los periódicos que se editan en Oaxaca serían el instrumento a utilizar para hacer una aproximación a la forma en la cual los medios de aquella entidad representan el fenómeno religioso.

Se debe aclarar que el universo de este análisis no estuvo constituido por todas las publicaciones diarias que se producen en Oaxaca, ni por todas las que circulan en su capital, sino por tres diarios que prácticamente han mantenido una publicación ininterrumpida en los últimos cinco años, y que poseen más de cinco mil números editados. Dichos periódicos son: 
- Diario Noticias ${ }^{12}$

- Diario El Extra ${ }^{13}$

- Diario El Imparcial ${ }^{14}$

Por cada uno de esos periódicos se tomó una muestra de 91 ejemplares; es decir, se analizaron un total de 273 diarios, correspondientes al periodo comprendido entre el $1^{\circ}$ de abril y el 30 de junio de 1998.

Los aspectos que registramos en nuestro seguimiento de la información religiosa fueron:

- Nombre de la publicación

- Fecha de la publicación

- Género periodístico

- Encabezado

- Asunto

- Nombre del autor

- Ubicación de la información (sección, página y columna)

- Religión o religiones citadas

- Fuente de la información

- Agentes religiosos implicados directamente

- Otros personajes e instituciones implicados indirectamente

No está por demás señalar que de este seguimiento fueron excluidos los anuncios, felicitaciones, esquelas, "Páginas de la Iglesia", mensajes episcopales, cartas a la redacción y todo tipo de publicaciones imposibles de enmarcar dentro de los géneros periodísticos. ${ }^{15}$

Además, realizamos breves entrevistas con los directores de los diarios que conformaron el universo de investigación, para interrogarles si contaban con periodistas especializados en asuntos religiosos en sus redacciones. Lo dicho en las entrevistas por los directores de los diarios se confrontó con un seguimiento de los autores de las informaciones publicadas.

Finalmente, para identificar algunos aspectos de las creencias y prácticas religiosas, así como de las concepciones morales y del conocimiento teórico que

12. El periódico Noticias tenía 21 años al 30 de junio de 1998 y había publicado 7,712 números. Su director era Ismael San Martín Hernández.

13. El Extra tenía 19 años al 30 de junio de 1998 y había publicado 5,747 números. Su director era Héctor Pablo Ramirez Leyva.

14. El diario El Imparcial tenía 47 años al 30 de junio, y había publicado 17,642 números. Su directora era Raquel Aparicio.

15. Los domingos El Imparcial y Noticias publican una sección especializada en asuntos de religión. 
poseen los periodistas, practicamos una encuesta a 30 de los trabajadores de los medios examinados.

La confección de dicho cuestionario se inspiró en un guión diseñado por el investigador Enrique Marroquín. ${ }^{16}$ Es preciso reconocer que aun cuando este instrumento arrojó datos interesantes, algunas limitaciones nos obligan a considerarlo sólo como un sondeo de opinión.

\section{Presentación de resultados}

El diario que publicó la mayor cantidad de notas sobre temas de religión fue $E l$ Imparcial, con un total de 172 registros.

En segundo lugar se ubicó Noticias, con 102, y en tercero El Extra, con un total de 46 informaciones.

Esto significa que en el mismo lapso, El Imparcial publicó una cantidad equivalente a 70.58 por ciento más de informaciones relacionadas con el fenómeno religioso que el diario Noticias, y aproximadamente cuatro veces más que El Extra.

\section{PROPORCION DE LAS CANTIDADES DE INFORMACION RELIGIOSA PUBLICADAS EN LOS DIARIOS ANALIZADOS}

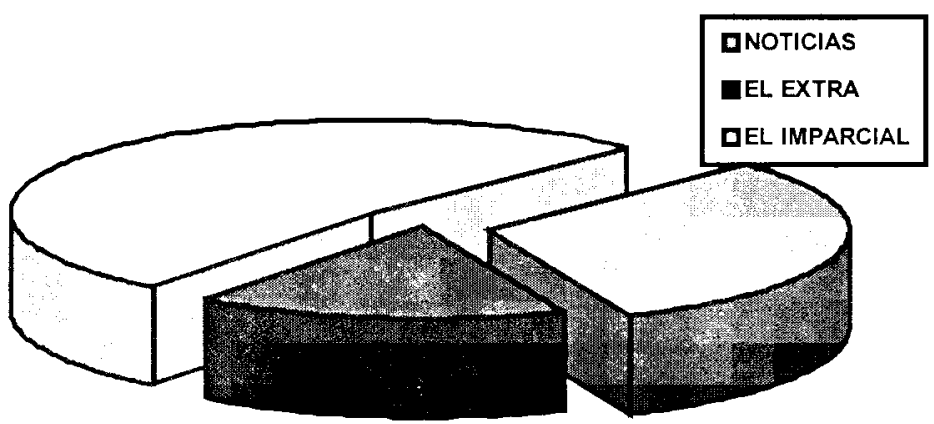

16. El "guión" originalmente fue elaborado por el investigador Enrique Marroquín para destinarse a una encuesta cuyo propósito era saber cómo entienden las categorías religiosas, creencias, prácticas rituales y concepciones morales los habitantes de algunas comunidades rurales y de la ciudad de Oaxaca. La interpretación de los resultados obtenidos en la aplicación de la encuesta del doctor Marroquín puede consultarse en la obra El botín sagrado: la dinámica religiosa en Oaxaca, del mismo autor, editada en 1992 bajo los auspicios del Instituto de Investigaciones Sociales de la UABJO, y la Dirección de Comunicación Social del Gobierno del estado de Oaxaca, dentro de la colección "Del Barro Nuestro". 


\section{Noticias y opiniones}

De las 172 informaciones publicadas por El Imparcial, 102 fueron notas, 54 artículos, editoriales, columnas o caricaturas, ${ }^{17}$ siete reportajes, cinco fotografías, tres crónicas y una entrevista.

De los 102 registros que fueron publicados en Noticias, 64 fueron notas; 11 artículos, editoriales, caricaturas o columnas; cuatro reportajes; 19 fotografías; cuatro crónicas y una entrevista. En el lapso al cual se limitó este análisis, 38 notas sobre asuntos o personajes religiosos fueron publicadas en la primera plana de Noticias. Todas estas se refirieron a la Iglesia católica.

Por lo que respecta a $E l$ Extra, de las 55 informaciones vinculadas a asuntos religiosos catorce fueron notas; 34 artículos, editoriales, caricaturas o columnas. Ningún reportaje o crónica, seis fotografías y una entrevista. Las informaciones de carácter religioso publicadas en la primera plana de El Extra fueron cinco y todas correspondieron al catolicismo.

Esta exploración inicial de los géneros periodísticos más utilizados para difundir información con contenidos religiosos, nos lleva a establecer que el diario Noticias publicó mayor información a través de los géneros periodísticos noticiosos, y sólo opinó en pequeña escala, originando una relación de 91 a once; El Extra diseminó una mayor cantidad de opiniones frente a la información noticiosa (34-21). El Imparcial dedicó dos tercios a la información noticiosa, y el resto a la opinión (118-54) resultando el más equilibrado.

\section{Origen geográfico de las informaciones}

Otra variable que se analizó en el seguimiento hemerográfico fue el origen de los acontecimientos que fueron publicados por los periódicos seleccionados. El 63.72 por ciento de la información religiosa publicada por el periódico Noticias se originó en el estado de Oaxaca; el 10.78 por ciento en otras regiones de México; y el 25.49 por ciento en el extranjero.

El 44.76 por ciento de información religiosa que publicó El Imparcial se originó en Oaxaca; el 28.48 procedió de otros lugares del país y el 20.93 por ciento procedió del extranjero. En el 5.83 por ciento de las notas no se encontró claramente definido el origen geográfico de la información.

17. De los cuatro géneros periodísticos de opinión se obtuvo la sumatoria global: 54 . Lo mismo sucede en la contabilización de las publicaciones de opinión en los otros dos periódicos. 
Del total de información relativa a temas religiosos que publicó El Extra, 69.09 por ciento procedió de fuentes locales; 10.9 por ciento partió de otras partes del territorio nacional y sólo 3.6 por ciento se originó en el extranjero. $\mathrm{Al}$ igual que El Imparcial, en El Extra enfrentamos algunos problemas para ubicar el lugar preciso en el cual se originó la información. Ese problema se presentó en 16.41 por ciento de los casos examinados.

Es posible establecer que la mayor parte de las informaciones que fueron publicadas en los rotativos que fueron objeto del presente análisis confirió prioridad a los asuntos locales como materia de prima de la información que se publicó respecto a temas religiosos.

\section{Sitios de interés}

El tercer elemento analizado correspondió a los actores y acontecimientos consignados en la prensa oaxaqueña.

\begin{tabular}{|l|c|}
\hline SITIOS DE INTERÉS El Imparcial & MENCIONES \\
\hline $\begin{array}{l}\text { Samuel Ruiz y otros asuntos de la Diócesis } \\
\text { de San Cristóbal de las Casas }\end{array}$ & 31 \\
\hline Juan Pablo II & 29 \\
\hline Caso del sacerdote asesinado en Oaxaca & 21 \\
\hline Héctor González, arzobispo de Antequera & 20 \\
\hline Manifestaciones de religiosidad popular & 15 \\
\hline Bartolomé Carrasco, obispo emérito de Oaxaca & 13 \\
\hline Miguel Alba Diaz, obispo auxiliar & 10 \\
\hline Arturo Lona, obispo de Tehuantepec & 9 \\
\hline Justo Mullor, nuncio apostólico & 9 \\
\hline Sacerdotes diocesanos & 5 \\
\hline Otros religiosos católicos en el mundo & 5 \\
\hline Vocero del Episcopado local & 4 \\
\hline Cardenal Norberto Rivera & 4 \\
\hline Juan Jerardi, sacerdote guatemalteco asesinado & 3 \\
\hline Evangélicos & 2 \\
\hline Religiosos islámicos & 1 \\
\hline Judios & 1 \\
\hline Obispo de Pakistán suicida & 1 \\
\hline \hline
\end{tabular}


En El Imparcial logramos establecer 18 sitios de interés, de los cuales el que admitió el mayor número de menciones fue el relativo a los asuntos de la diócesis de San Cristóbal de las Casas, Chiapas y, en especial, las notas relacionados con las actividades de Samuel Ruiz.

En segundo lugar se situaron las informaciones desprendidas de las actividades del Papa Juan Pablo II y en tercer sitio las noticias y opiniones que se difundieron en torno al asesinato del sacerdote Juan Ortiz Carreño.

Los sitios de interés relacionados con asuntos de religiones diferentes a la católica sumaron solamente tres.

\begin{tabular}{|l|c|}
\hline SITIOS DE INTERÉS Noticias & MENCIONES \\
\hline Sacerdotes diocesanos de Oaxaca & 19 \\
\hline Héctor González, arzobispo de Antequera & 16 \\
\hline Juan Pablo II & 15 \\
\hline Manifestaciones de religiosidad popular & 9 \\
\hline Bartolomé Carrasco, obispo emérito de Oaxaca & 8 \\
\hline Otros obispos mexicanos & 6 \\
\hline Justo Mullor, nuncio apostólico & 4 \\
\hline Arturo Lona, obispo de Tehuantepec & 4 \\
\hline Miguel Alba Díaz, obispo auxiliar & 2 \\
\hline Vocero del Episcopado local & 2 \\
\hline Juan Jeraldi, obispo guatemalteco asesinado & 2 \\
\hline Samuel Ruiz y otros asuntos de la diócesis & 2 \\
de San Cristóbal de las Casas & \\
\hline Religiosos islámicos & 1 \\
\hline Conferencia Episcopal Mexicana (cEM) & 1 \\
\hline Obispo de Pakistán suicida & 1 \\
\hline Caso sacerdote asesinado en Oaxaca & 1 \\
\hline Cardenal Norberto Rivera & 1 \\
\hline Iglesia de Jesucristo de los últimos dias & 1 \\
\hline
\end{tabular}

El periódico Noticias consignó informaciones de carácter noticioso y uc opinión, las cuales concentramos en 18 sitios de interés.

Los personajes más citados en la información que analizamos pertenecen a la Iglesia católica: Héctor González - arzobispo de Antequera-, el Papa Juan Pablo II y, por razones coyunturales, el clero diocesano de Oaxaca.

Este periódico concedió una importante cobertura a las manifestaciones de la religiosidad católica popular, pues consignó la celebración de fiestas y celebraciones tradicionales, como el día de la Santa Cruz - el 3 de mayo-, y las 
representaciones del Vía Crucis en barrios, colonias y poblaciones de Oaxaca durante la Semana Santa.

Informaciones relacionadas con asuntos de religiones distintas a la católica resultaron notoriamente raquíticas.

\begin{tabular}{|l|c|}
\hline SITIOS DE INTERÉS DIARIO EI Extra & MENCIONES \\
\hline Sacerdotes diocesanos de Oaxaca & 17 \\
\hline Miguel Alba Díaz, obispo auxiliar & 9 \\
\hline Manifestaciones de religiosidad popular & 1 \\
\hline Bartolomé Carrasco, obispo emérito de Oaxaca & 5 \\
\hline $\begin{array}{l}\text { Samuel Ruiz, asuntos de la diócesis de San } \\
\text { Cristóbal de las Casas e información relativa a los } \\
\text { obispos de la Región Pacífico Sur }\end{array}$ & 4 \\
\hline Héctor González, arzobispo de Antequera & \\
\hline Arturo Lona, obispo de Tehuantepec & 4 \\
\hline Justo Mullor, nuncio apostólico & 4 \\
\hline Cardenal Norberto Rivera & 1 \\
\hline
\end{tabular}

El total de "sitios interés religioso" identificados en El Extra fue de nueve. El rubro que admitió mayores menciones fue el denominado "sacerdotes diocesanos". Sin embargo, ese "sitio de interés" puede considerarse como coyuntural, pues se originó a raíz del asesinato del presbítero Juan Ortiz Carreño, ocurrido en mayo. Ese mes El Extra se dedicó a consignar opiniones - muy agrias, por cierto-, sobre el impacto que causó en la Iglesia católica el referido asesinato.

El segundo sitio de interés más mencionado correspondió a Miguel Alba Díaz, obispo auxiliar de Oaxaca, quién fue objeto de duras críticas por los periodistas a causa del sentido de sus prácticas pastorales -en pro de las clases sociales económicamente más deprimidas de Oaxaca-.

Este periódico no publicó ningún tipo de información relacionada con otras religiones.

\section{Análisis de los tres diarios}

De 45 "sitios de interés" que logramos determinar en los tres periódicos que fueron objeto de nuestro seguimiento hemerográfico, el 84.44 por ciento correspondió a miembros de la Iglesia católica -en su gran mayoría altos representantes de ésta. El resto se orientó a las manifestaciones de religiosidad popular y algunos asuntos vinculados a otras religiones, como la islámica y la judía. 
El clero diocesano es la fuente de información religiosa más importante para los periódicos locales de hecho, en términos generales, fue el "sitio de interés" que mayores menciones observaron en la prensa.

Sin embargo, hay que aclarar que su presencia se debió a un suceso extraordinario, y se restringió al mes de mayo, ya que en junio, al "enfriarse" la noticia de la muerte del padre Ortiz Carreño, ese sector volvió a ser una fuente secundaria para los periodistas.

Los resultados expuestos en las tablas anteriores ponen de manifiesto que el titular de la Diócesis de San Cristóbal de las Casas -Samuel Ruiz-, así como Héctor González - arzobispo de Oaxaca-, fueron los actores religiosos que merecieron mayor atención en los diarios analizados. El Papa Juan Pablo II ocupó el tercer sitio.

\section{Los autores de la información}

Otro de los aspectos explorados en esta aproximación tuvo que ver con la autoría de las informaciones publicadas. El objetivo fue tratar de establecer los niveles de especialización de los periodistas oaxaqueños sobre el tema.

Para efectos de ese análisis se preguntó a los directores de los tres diarios si en ellos laboraban personas efectivamente especializadas en "cubrir" la fuente "religión".

Únicamente la directora de El Imparcial reconoció que, debido a la alta rotación de personal que se presentaba en ese periódico, en ese diario no había personas dedicadas exclusivamente a tratar los asuntos de religión.

Los directores de Noticias y El Extra afirmaron que en su cuerpo de reporteros sí contaban con especialistas dedicados al tema. Sin embargo, el seguimiento hemerográfico que realizamos arrojó los siguientes resultados.

\section{Resultados del seguimiento hemerográfico}

Quince personas publicaron sobre temas de religión en El Extra. El periodista Hugo Rodríguez lo hizo en nueve ocasiones y Pablo Ramírez publicó cinco notas sobre el tema.

En El Imparcial, 35 personas publicaron y firmaron artículos, columnas, caricaturas, fotografías, notas, crónicas o reportajes relativos a asuntos religiosos. Quien con mayor frecuencia lo hizo fue la reportera Olga Rosario Avenda- 
ño, con un total de diez notas. La reportera Gisela Ramírez fue responsable de nueve publicaciones.

Dos reporteros escribieron sobre asuntos religiosos en siete ocasiones: José Hannan y César Morales. El caricaturista Bolaños dedicó seis cartones al asunto que nos ocupa. Las treinta personas restantes abordaron el tema de nuestro interés en menos de cuatro ocasiones.

Los periodistas de El Imparcial generaron 51.74 por ciento de la información sobre asuntos religiosos que se publicó en ese diario. La información restante procedió de agencias nacionales e internacionales. De ese 51.74 por ciento, 71.37 por ciento fue firmado por cinco periodistas.

Por lo que respecta al periódico Noticias, un total de diecisiete personas escribieron sobre asuntos religiosos. El reportero Octavio Vélez fue quien más publicó sobre el tema (29 notas). Lejos de él se situaron el reportero Raciel Martínez y el columnista "Platón" con cuatro.

Los catorce periodistas restantes abordaron el tema en menos de cuatro ocasiones. Los periodistas de Noticias produjeron 63 notas en torno al tema religioso, cantidad que equivale a 61.76 por ciento de las informaciones publicadas sobre asuntos religiosos por ese diario. El 38.24 restante fue información obtenida de las agencias nacionales e internacionales.

Un periodista de Noticias fue autor de casi la mitad de la información local sobre religión que manejó ese diario por espacio de tres meses.

\section{Conclusiones}

En el lapso comprendido entre abril y junio de 1998, de las notas relativas a instituciones, actores y asuntos de orden religioso que consignaron los periódicos analizados, destacaron las actividades realizadas por un minúsculo grupo de ministros del catolicismo.

El papa Juan Pablo II, y los sacerdotes Samuel Ruiz y Héctor González Martínez con mayor frecuencia aparecieron en la prensa local.

La fuerte presencia de González Martínez en los medios admite gran relevancia, pues representa, según los especialistas, "la tendencia a volver a la Gran Disciplina, volver a una Iglesia clerical centralizada, ortodoxa; a la moral tradicional y a la continencia puritana, que cierra la posibilidad de pluralizar el espacio religioso". 18

También quedó claro que existe una marcada tendencia a publicar notas relacionadas con la religiosidad popular católica tradicional. Esa situación tal

18. Enrique Marroquín: La Iglesia y el poder, Dabar, México, 1993, página 118. 
vez represente un intento por tender lazos de encuentro con el pueblo creyente, ofreciéndole un espacio de representación. Pero eso sólo ocurre con el sector católico. De hecho, la presencia de otros sectores religiosos sólo se registra, como hemos visto, en situaciones "anormales", es decir, cuando ocurre algo especial.

Mientras los periódicos Noticias y El Imparcial proporcionan mayor información -aunque sólo referida a las diversas tendencias y manifestaciones de la religión católica-, El Extra consignó opiniones poco constructivas, advirtiéndose en éste una línea editorial inclinada en favor del conservadurismo religiosopolítico.

Este breve análisis de contenido deja entrever que la prensa oaxaqueña está asumiendo posturas excluyentes. En la difusión de noticias está evidenciando que en torno a los asuntos religiosos hay un "nosotros" y un "ellos".

El "nosotros" supone lo católico, mayoritario y conservador. En cambio, "ellos" remiten a lo susceptible de interpretarse como "no católico", lo católico contestatario o simplemente minoritario. Al parecer, los diarios analizados piensan que las minorías son menos confiables y sólo merecen atención periodística cuando se les percibe como generadores de problemas, crímenes y violencia -como en el caso del asesinato del sacerdote Juan Ortiz.

Conforme a lo observado, es posible advertir que el discurso noticioso, está contribuyendo a la reproducción de una religiosidad intolerante en Oaxaca.

\section{Lo que reveló una encuesta}

Con el objetivo de identificar algunos aspectos de las creencias y prácticas religiosas, así como de las concepciones morales y del conocimiento teórico de los periodistas sobre el tema religión, encuestamos a treinta trabajadores de los medios examinados.

Los cuestionarios comprendieron cuarenta preguntas y fueron entregados a los periodistas en sus centros de trabajo. Tomando en consideración sus apretadas agendas, se les dio un plazo de 36 horas para que devolviesen los cuestionarios. Veinticuatro periodistas así lo hicieron, uno se negó a contestar nuestras preguntas - sin explicar siquiera los motivos-, y cinco periodistas no entregaron el cuestionario a tiempo, por lo que esos cuestionarios tuvieron que ser descartados. 


\section{Información general}

Se pudo establecer que los periodistas que laboran en los tres diarios analizados tienen una edad promedio de 31.05 años. A pesar de la notoria presencia de las mujeres en las redacciones, éstas todavía son minoría y constituyen poco más de un tercio del personal de esos centros de trabajo ( 36.85 por ciento).

Más de la mitad de los periodistas poseen estudios universitarios (57.89 por ciento). 21.05 por ciento desempeñan la profesión contando con certificados de educación preparatoria y el 21.05 por ciento posee niveles escolares de secundaria o de educación primaria.

El 36.84 por ciento de los encuestados manifestó tener cinco años o más trabajando en la misma empresa. El 15.78 por ciento afirmó tener entre tres y cinco años de antigüedad, el 15.78 por ciento aseguró tener un año laborando y el 26.31 por ciento menos de un año.

\section{Preferencia, creencias y prácticas religiosas}

$\mathrm{Al}$ indagar en las preferencias y prácticas religiosas de los periodistas fue posible confirmar que el porcentaje de católicos es muy alto: 73.68 por ciento. El 5.26 por ciento se declararon protestantes y el 21.05 por ciento manifestó no practicar ninguna religión.

El 63.15 de los periodistas encuestados confesó creer en los santos, en tanto que el 68.42 por ciento afirmó creer en la Virgen. No obstante, el 63.15 por ciento señaló que no creía en la resurrección de los muertos, y en igual proporción los periodistas manifestaron su escepticismo respecto a la existencia de "el diablo".

El 42.10 por ciento ha recurrido a suertes de adivinación, admitiendo haber consultado las cartas o la lectura del café por lo menos en una ocasión.

En lo que se refiere a las prácticas institucionales religiosas, el 73.69 por ciento afirmó no participar nunca en actividades religiosas. El 21.05 por ciento manifestó que lo hacía "a veces", y sólo el 10 por ciento expresó que lo hacía con cierta frecuencia.

\section{Moral}

Para hurgar en algunos aspectos de la moralidad de los periodistas en relación con los asuntos religiosos y sociales, se preguntó qué opinaban sobre el famoso 
robo de la corona de la Virgen de la Soledad, cometido a principios de esta década. ${ }^{19}$

Para el 20 por ciento de los encuestados, el robo representó un acto sacrílego. El 50 por ciento afirmó que tal acto reflejaba la degradación moral de los humanos y el 30 por ciento restante calificó ese robo como un delito cualquiera.

$\mathrm{Al}$ cuestionarles sobre la manera en la cual norman sus actos, el 78.94 por ciento afirmó que actúa de acuerdo con su conciencia y sólo el 21.05 por ciento afirmó obrar de acuerdo con los mandamientos establecidos por Dios.

Sobre cuál consideran que es el principal problema que enfrenta la humanidad, la destrucción irreversible de los recursos naturales se situó como principal preocupación ( 32.35 por ciento). El segundo lugar correspondió a la desintegración familiar (23.52 por ciento). La pobreza recibió el tercer lugar (17.64 por ciento). Problemas sociales como el aborto, el alcoholismo y la promiscuidad recibieron las últimas menciones en las preocupaciones de los informadores (2.94 por ciento).

\section{Concepción sobre los ministros de culto}

Respecto a los sacerdotes y pastores religiosos, el 30 por ciento de los encuestados los calificó como "personajes que se aprovechan de la fe del pueblo"; el 40 por ciento los consideró "líderes espirituales"; y 15 por ciento los llamó "representantes de Dios en la Tierra". Un porcentaje similar los señaló como "administradores de los sacramentos".

Para el 63.15 por ciento de los encuestados, la política y la religión son dos campos separados y "los sacerdotes no deben mezclarse en asuntos del gobierno".

A pesar de que los periodistas podrían asumir una concepción más liberal respecto a asuntos religiosos, resultó interesante descubrir que más de la mitad de los encuestados (55 por ciento) consideró a los ministros católicos como "líderes espirituales" y "representantes de Dios en la Tierra".

19. Hace poco menos de diez años se registró en la capital de Oaxaca un acto delictivo que los medios de comunicación denominaron como: "El robo de las joyas de la Virgen de la Soledad". Dicho robo ocurrió en la Basílica Menor de la Soledad, dedicada a la veneración de la advocación mariana del mismo nombre y suscitó gran polémica entre el clero, las autoridades de justicia y el pueblo. Hubo misas de desagravio, reclamos airados y hasta incitaciones por parte de algunos locutores de la radio local —como el señor Alejo Vásquez-, para actuar en contra del entonces arzobispo en funciones, Bartolomé Carrasco Briseño, a quien señalaba como cómplice de los ladrones. A casi una década de distancia el asunto todavía no se resuelve y, a decir de muchos católicos, "la herida sigue abierta y duele". 
También fue interesante descubrir que un sector mayoritario ( 65 por ciento) piense que los ministros religiosos no deben inmiscuirse en política.

\section{Percepción respecto a religiones no católicas}

Este rubro es uno de los más importantes para el análisis que se presenta, ya que con base en las respuestas obtenidas se puede tener una idea de la manera en que los periodistas conciben el reacomodo religioso.

Para el 50 por ciento de los informadores encuestados, los grupos religiosos protestantes son una amenaza para la nación y forman parte de una conjura de Estados Unidos para destruir al país.

El 57.89 por ciento de los periodistas consideraron que los grupos no católicos que están ingresando a Oaxaca no deben considerarse una alternativa religiosa en relación con el catolicismo.

\section{Conocimiento teórico}

Se les pidió a los periodistas encuestados mencionar los nombres de tres dioses prehispánicos: 42.10 por ciento pudo señalar tres.

Se les solicitó explicaran qué es el sincretismo: 21.05 por ciento lo hizo adecuadamente.

La diferencia entre secta y religión pudo ser explicada únicamente por 15.78 por ciento de los encuestados, en tanto 15.6 por ciento contestó de manera acertada qué es el "fundamentalismo religioso".

Si se toma en cuenta que casi 74 por ciento de los encuestados son católicos, y que tienen como libro sagrado La Biblia, podemos afirmar que el 26 por ciento que enumeró correctamente los libros que conforman "El Pentateuco" representa un sector muy reducido.

Sólo 5.2 por ciento sabía que el mixteco fue la primera lengua prehispánica a la cual precisamente se tradujo La Biblia.

Finalmente, el 57.2 por ciento respondió acertadamente que El Corán es el libro sagrado de los musulmanes. 


\section{Conclusiones}

En Oaxaca, el avance de los movimientos protestantes está dejando de ser marginal, por lo que sus conflictos y las formas de relación que establecen con grupos más poderosos se convierten en aspectos interesantes para el estudio de lo religioso desde lo comunicacional, no tanto por la conversión individual, sino por el significado del movimiento sociorreligioso, el cual, junto con otros fenómenos y expresiones religiosas son consignados u omitidos en la prensa, al parecer de manera más causal que casual, tras haber pasado por las mediaciones que significan la coyuntura social, política y económica; las directrices comerciales de los periódicos, la línea editorial, la agenda de las redacciones y, en última instancia, las preferencias, prejuicios, marco de valores, conocimiento teórico y la propia experiencia religiosa de los periodistas.

El fenómeno de la conversión religiosa parece no haber sido advertido aún por la prensa local, o tal vez ésta todavía no ha dimensionado su importancia. Los resultados obtenidos en el "rastreo" de periódicos así parecen confirmarlo. Las causas pueden ser muchas, pueden ser de carácter comercial - no hay que olvidar que las noticias se compran y se venden, y que las fuerzas del mercado determinan muchas de sus características. ${ }^{20}$

El poder está basado en un acceso privilegiado a los recursos socialmente valorados. Lo mismo sucede en el caso del acceso al discurso público, por ejemplo, al de los medios. ${ }^{21}$ En ese sentido, la Iglesia católica local, en especial la jerarquía que opera en Oaxaca, puede ser definida como institución de élite, la cual se define por sus amplias posibilidades de acceso al discurso público y a otros discursos y acontecimientos comunicativos de relevancia, no así las minorías que profesan otros credos o los propios grupos católicos beligerantes.

Nuestra encuesta nos permitió confirmar que el diario Noticias es el único de los tres periódicos analizados que cuenta con personal dedicado ex profeso a cubrir información religiosa. El origen de esa situación tal vez pueda encontrarse en la falta de formación y consolidación de equipos duraderos de informadores en los otros dos periódicos, cosa que sin duda tiene que ver con la necesidad urgente de mejorar las condiciones salariales y otras demandas de carácter laboral en esas empresas.

Con base en los resultados que arrojó nuestra encuesta, podemos decir que entre los informadores se está gestando un proceso de secularización, el cual no les ha impedido mantener elementos importantes de su religiosidad católica. El

20. A. Teun van Dijk: "Prensa, racismo y poder". Cuadernos del Posgrado en Comunicación, UIA, número 3, México, 1994, página 78.

21. Ibid. 
rasgo más llamativo radica en que por lo menos la mitad de los periodistas, $a$ priori considera a los grupos religiosos no católicos como negativos para el país. Esa cuestión resulta preocupante, más si se toma en cuenta que los informadores de El Extra, El Imparcial y Noticias, aún cuando en su mayoría cuentan con estudios universitarios, demostraron carecer en lo general de conocimientos básicos sobre asuntos religiosos, necesarios para no caer en determinismos. De esto se deduce que su postura está profundamente prejuiciada.

De una manera dolorosa pero irrefutable, Jean Pierre Bastian, el reconocido investigador de asuntos religiosos, afirmó que

entre muchos científicos sociales y en la gran mayoría de los periodistas reina la confusión y el desconocimiento para definir el fenómeno religioso, lo cual ha ocasionado la satanización de los herejes y los disidentes. ${ }^{22}$

Los resultados de nuestra investigación afirman la validez de las tesis de Bastian. En Oaxaca la satanización y exclusión de la prensa no sólo se ha dado $a$ priori en relación con los grupos protestantes, sino incluso en relación con sectores católicos minoritarios, los cuales se revelan ante las disposiciones de una jerarquía muchas veces vinculada a poderos grupos de poder político y económico.

¿Los periódicos anticipan la opinión pública o sólo la reflejan? Los medios constituyen el entorno cuya presión desencadena la combatividad, la sumisión o el silencio.

Según Elizabeth Noëlle Newman: "la opinión de las minorías bajo esas condiciones, se convierte en una opinión que en adelante no se puede contradecir sin correr el riesgo de alguna sanción. De este modo pasa de la jerarquía de simple opinión de una facción, a la opinión pública". ${ }^{23}$

Sin embargo, antes de que ocurra este posicionamiento en el espacio público por parte de las minorías, si los medios locales no ponen atención a las modificaciones del entorno religioso y se anticipan ofreciendo información clara y detallada sobre el reacomodo que se está gestando, es muy probable que se susciten casos de intolerancia por parte de las mayorías que se sientan en peligro.

No hay que olvidar que en la actualidad el individuo depende casi totalmente de los medios de comunicación masiva, tanto en lo que se refiere a los hechos mismos como a la evaluación del clima de opinión y, por regla general, reaccionará ante la presión de la opinión en la forma en que ésta se ha hecho pública.

22. Véase Jean-Pierre Bastian: "Disidencia religiosa protestante e imperialismo en México", en La participación de los cristianos en el proceso popular de liberación en México, Siglo XXI Editores, pp. 300-301.

23. Elizabeth Noëlle Newman: "La espiral del silencio", en Nuevo espacio público, Jean-Marc Ferry (comp.), Gedisa, México, 1997, páginas 200-207. 
El campo religioso oaxaqueño se encuentra en proceso de reacomodo, y es preciso que los medios no desdeñen esa nueva realidad, que anticipen posibles escenarios conflictivos y estén prestos a abrir sus páginas a los fenómenos religiosos que están emergiendo con gran fuerza.

No se trata de estar a favor o en contra de la disolución o de la permanencia de las creencias, de la fe, de las costumbres, y de las tradiciones de la Iglesia católica. Es preciso que en los medios de comunicación aparezcan las otras verdades y hagan posible, a través de su acción, como afirma Martín- Barbero, ${ }^{24}$ que el pluralismo que ha vivido arrinconado en círculos intelectuales o restringido a cortos momentos de "hegemonía liberal" se despliegue en nuestras ciudades y en nuestros países, haciendo posible la convivencia del catolicismo con otras religiones, la presencia creciente de las sectas protestantes y una secularización progresiva de las costumbres y de las ideas. Tal situación hará visible y aceptable una concepción nueva de la identidad, no hecha de aparentes fundamentos y raíces sino de relaciones e interacciones.

24. Jesús Martín-Barbero: "La comunicación plural: alteridad y socialidad", en Diá-Logos, número 40, Revista de la Federación Latinoamericana de Facultades de Comunicación Social, Bogotá, 1994, página 76. 